\title{
The effects of levosimendan on renal functions in open-heart surgery patients with a low ejection fraction
}

\author{
Süleyman Yazıc1 ${ }^{1}$, Mehmet N. Karabulut ${ }^{1}$, Ayşe Baysal ${ }^{2}$, Rahmi Zeybek $^{3}$ \\ ${ }^{1}$ BASSAKŞEHIR ÇAM VE SAKURA CITY HOSPITAL, DEPARTMENT OF CARDIOVASCULAR SURGERY, ISTAANBUL, TURKEY \\ ${ }^{2}$ PENDIK BAYPARK HOSPITAL, DEPARTMENT OF ANESTHESIA AND REANIMATION, İSTANBUL, TURKEY \\ ${ }^{3}$ PENDIK BÖLGE HOSPITAL. DEPARTMENT OF CARDIOVASCULAR SURGERY. ISTANBUL. TURKEY
}

\begin{abstract}
Purpose. This study investigated the effects of levosimendan on renal functions in patients with a preoperative low ejection fraction undergoing open-heart surgery and cardiopulmonary bypass (CPB). Materials and Methods. The study retrospectively evaluated 64 patients with a diagnosis of mitral valve insufficiency and left ventricular dysfunction undergoing open-heart surgery with CPB. Patients were divided depending on the preoperative blood creatinine level less (Group 1) or more than $1.2 \mathrm{mg} / \mathrm{dL}$ (Group 2). A bolus dose of levosimendan was administered through the aortic arch at the end of the CPB, preceding an infusion of levosimendan intravenously in all patients. Demographic data, preoperative and 48-hour postoperative echocardiographic studies were done. The blood urea and creatinine levels were collected preoperatively and on postoperative days 1, 3, and 10. The use of inotropic support, intra-aortic balloon pump, and complications were recorded. Results. The demographic data were similar between groups (p>0.05). Preoperative serum creatinine levels were higher in Group 1 in comparison to Group 2 ( $\mathrm{p}=0.01, \mathrm{p}<0.001$, respectively). The aortic cross-clamp and cardiopulmonary bypass times were similar between groups $(p>0.05)$. Preoperative serum creatinine levels were higher in Group 1 in comparison to Group $2(\mathrm{p}<0.001)$. On postoperative day 1 , serum creatinine levels of Group 1 were significantly lower than Group $2(\mathrm{p}<0.001)$. On postoperative days 3 and 10 , no differences were observed regarding serum creatinine levels between groups ( $p>0.05$ ). Complications were similar between groups $(\mathrm{p}>0.05)$. Conclusions. In patients with low ejection fraction undergoing open-heart surgery, the use of levosimendan intraoperatively and 24 hours postoperatively prevents deterioration of renal functions in patients with or without preoperative disturbance in serum creatinine level.
\end{abstract}

\section{Introduction}

Heart failure is a progressive systemic perfusion disorder which consists of hemodynamic deterioration, diminished exercise capacity, activation in the neurohormonal mechanisms. The most commonly encountered reasons for heart failure include; decrease in the myocardial contractility and activation in the sympathetic and renin-angiotensin systems [1]. Positive inotropic agents are frequently used in patients with decompensating heart failure and left ventricular systolic dysfunction. For this reason, beta-adrenergic drugs, dobutamine and dopamine, or phosphodiesterase inhibitors, milrinone and enoximone, are often administered however, these agents have been reported to increase morbidity and mortality in heart failure [2,3]. Levosimendan is a calcium sensitizer that has a positive inotropic action as well as peripheral and coronary vasodilation by opening of the ATP-sensitive potassium channels [4]. This dual mechanism of action results in an improved myocardial contractility without increase in myocardiac oxygen consumption that has been reported to decrease the myocardial ischemic events after cardiopulmonary bypass [4,5]. The positive inotropic action of levosimendan is due to its binding to troponin $\mathrm{C}$ which facilitates the interaction between actin and myosine filaments without changes in intracellular $\mathrm{Ca}++$ ion concentrations.

There is neither an increase in the amount of consumption of ATP nor a reduction in the relaxation time in diastole. In the vascular smooth muscle, vasodilatation occurs by the opening of the ATP related $\mathrm{K}+$ channels. In summary, the clinical effects of the levosimendan are related to its inotropic action, decrease in preload and afterload along with no increase in myocardial oxygen demand [3-5]. 
In congestive heart failure, it has been reported that there is moderate amount of increase in the levels of blood urea and creatinine secondary to a reduction in the renal blood flow and glomerular filtration rate [6]. In addition to renal hypoperfusion, intrarenal vasoconstriction has been reported to occur due to activation of the renin angiotensin system and increase in the blood levels of vasopressin, endothelin and catecholamines [7]. Various pathophysiological mechanisms cause decrease in renal perfusion and development of ischemic tubular necrosis in patients with heart failure [8].

The postoperative incidence of acute kidney injury (AKI) ranges between $0.33 \%$ and $9.5 \%$ following cardiac surgery with cardiopulmonary bypass (CPB) [9]. The postoperative development of renal insufficiency after cardiac surgery is usually associated with poor outcome and high in-hospital mortality [10]. Recently, there are studies on development of the best efficient scoring system to detect patients at risk of postoperative renal failure following cardiac surgery. The Cleveland score system evaluates preoperative risk factors including; age, gender, history of congestive heart failure, diabetes that required medical treatment or insulin therapy, chronic obstructive pulmonary disease that was treated with bronchodilators, previous cardiac surgery, preoperative serum creatinine ( $\mathrm{sCr}$ in $\mathrm{mg} / \mathrm{dl}$ ), preoperative ventricular function (assessed either by angiography or by echocardiography), presence of an intra-aortic balloon pump before surgery, type of cardiac surgery (isolated coronary artery bypass graft (CABG), valve procedures, combined $\mathrm{CABG}$ and valve surgery, and other major surgical procedures), and operative status (elective, urgent, or emergent) to determine the risk of development of AKI after cardiac surgery [9-11].

The protective effects of levosimendan on renal functions have been demonstrated by the studies that provided data on improvement in renal blood flow after establishment of hemodynamic stability [12] and potent vasodilatory action by the agonistic effects on K-ATP channels [13]. Levosimendan has been reported to have anti-inflammatory actions as well as various actions at cellular level of renal system such as reversal of AT-2 mediated mesangial cell contraction with consequent increase in glomerular capillary surface area and glomerular filtration rate that inhibits the injury of the renal tubular functions. In general, levosimendan acts mainly by an increase in renal blood flow and enhancement of glomerular filtration rate [14,15].

An important effect of levosimendan is its potential to improve renal function that is shown by a reduction in serum creatinine levels in patients with decompensated acute heart failure $[5,6,9,16]$. The recent guidelines of the European Society of Cardiology suggest the use of levosimendan in cases of symptomatic low cardiac output heart failure secondary to cardiac systolic dysfunction $[1,2,16]$.

Although recent guidelines suggests that levosimendan is an effective in low cardiac output heart failure, there is an ongoing debate on whether levosimendan is effective for improving renal functions in open-heart surgery or not. Therefore, we aimed to discuss our findings with recent data in the literature and to evaluate the effects of calcium sensitizer levosimendan on renal functions in patients with a preoperative low ejection fraction undergoing open-heart surgery with CPB.

\section{Materials and Methods}

Between July 12009 and June 30 2011, a retrospective study design was conducted on 64 patients diagnosed with mitral valve insufficiency and left ventricular dysfunction. Surgery A Local Ethical Committee approval was obtained from Istanbul Provincial Health Directorate Kartal Kosuyolu High Speciality Educational and Research Hospital, Istanbul, Turkey, Ethical Committee Approval Number: 2013.2/1.

During surgical operation of all patients mitral reconstruction and ring annuloplasty were performed depending on pathological findings on mitral valve. If coexisting coronary artery disease was detected, coronary artery bypass graft (CABG) operation was performed. Patients with aortic valvular disorders were excluded from the study.

Table 1. Risk factors and points in Cleveland Score

\begin{tabular}{|c|c|}
\hline Risk factors & Cleveland points \\
\hline Female gender & 1 \\
\hline History of $\mathrm{CHF}^{*}$ & 1 \\
\hline $\mathrm{LVEF}^{*}$ & 1 \\
\hline$<40 \%$ & 1 \\
\hline Preoperative IABP* & 2 \\
\hline COPD* treated with bronchodilators & 1 \\
\hline $\begin{array}{l}\text { Diabetes that required treatment with } \\
\text { insulin }\end{array}$ & 1 \\
\hline Previous cardiac surgery & 1 \\
\hline \multicolumn{2}{|l|}{ Type of surgery } \\
\hline Valvular & 1 \\
\hline Combined CABG*+valvular & 2 \\
\hline Other surgeries & 2 \\
\hline \multicolumn{2}{|l|}{ Preoperative renal function; $\mathrm{sCr} *(\mathrm{mg} / \mathrm{dL})$} \\
\hline 1.2 to 2.09 & 2 \\
\hline$\geq 2.10$ & 5 \\
\hline \multicolumn{2}{|l|}{ Operative status } \\
\hline Emergent & 1 \\
\hline Score range & 0 to 17 \\
\hline \multicolumn{2}{|c|}{$\begin{array}{l}\text { Abbreviations: CHF; congestive heart failure, IABP; } \\
\text { intra-aortic balloon pump, COPD; chronic } \\
\text { obstructive pulmonary disease, CABG; coronary } \\
\text { artery disease, sCR; serum creatinine }\end{array}$} \\
\hline
\end{tabular}


Patients were divided into two groups depending on the preoperative serum creatinine level less (Group 1) or more than $1.2 \mathrm{mg} / \mathrm{dL}$ (Group 2). The Cleveland score system evaluates preoperative risk factors to detect patients at risk of postoperative renal failure following cardiac surgery and uses serum creatinine level of $1.2 \mathrm{mg} / \mathrm{dL}$ in its scoring system to calculate the risk to develop renal insufficiency postoperatively (Table 1) [10,11].

The inclusion criteria to study include: patients undergoing valve surgery and/or CABG with a preoperative ejection fraction of $40 \%$ or less were included into the study. Exclusion criteria include: emergent operation, normal echocardiographic study, aortic valve disease, chronic renal and liver disease, insulin dependent diabetes mellitus, severe obstructive and/or restrictive lung disease, infective endocarditis.

\section{Parameters}

The collected demographic data include; age, weight, height, body mass index and gender. The cardiovascular risk factors including; diabetes mellitus, hypertension, hypercholesterolemia, obesity, history of smoking as well as history of chronic obstructive pulmonary disease and peripheral vascular disease were sought. Lung functions were evaluated by radiographic studies of chest and lung function tests. Electrocardiogram was obtained routinely in preoperative and postoperative periods to detect rhythm disturbances. Preoperative and 48-hour postoperative echocardiographic studies were performed to evaluate the ejection fraction and valvular functions by the same cardiologist using Vivid 3 echocardiography (Vivid 3, Berlin, Germany).

The blood urea and creatinine levels were collected preoperatively and on postoperative day 1,3 and 10 . Prognostic risk parameters that have influence on morbidity and mortality were collected and these include; aortic cross-clamp, and cardiopulmonary bypass time, the use of inotropic support and intra-aortic balloon pump and prognostic risk factors influencing morbidity and mortality such as prolonged mechanical ventilation, development of pneumonia, myocardial infarct, cerebrovascular event, development of low cardiac output syndrome, atrial fibrillation and other rhythm disturbances, need for renal replacement therapies and dialysis, need for permanent pacemaker, reoperation secondary to bleeding, intensive care unit and hospital stay [17].

The induction and maintenance of anesthesia.

Routine monitoring for cardiac anesthesia was established prior to induction of anesthesia and these include; 5-lead electrocardiogram, radial artery catheterization, pulse oximetry, central venous catheter (7.5 or 8 French), urine catheterization and esophageal temperature probe. After premedication with oral benzodiazepine at an appropriate dose, standard anesthesia induction was administered with intravenous doses of midazolam (Roche, Basel, Switzerland) at a dose of $0.2 \mathrm{mg}$ kg-1, fentanyl (Janssen-Cilag, Beerse, Belgium) at a dose of 5 to $10 \mathrm{mcg} \mathrm{kg}-1$ and pancuronium (Organon, Turkey) at a dose of $0.1 \mathrm{mg} \mathrm{kg}-1$ were administered. For maintenance, all patients received sevoflurane at an endtidal concentration of $0.5 \%$ to $2 \%$ and intravenous maintenance doses of midazolam and fentanyl every hourly. Administration of levosimendan during the operative procedure was performed by an anesthesiologist. At the end of CPB, a bolus dose of levosimendan (SimdaxTM, Orion Pharma, Finland), was administered at a dose of $100 \mathrm{mg}$ in $50 \mathrm{ml}$ of $5 \%$ dextrose solution through aortic arch before cross clamp opening. After removal of $\mathrm{CPB}$, a continuous infusion of levosimendan was administered from a central venous catheter intravenously for 24 hours in all patients at a dose of $0.1 \mathrm{mcg} \mathrm{kg}-1 \mathrm{~min}-1$.

The operation procedure.

Median sternotomy was performed on all patients. Before the beginning of the CPB, heparin at a dose of 300 IU kg-1 was administered intravenously to keep the ACT (Active Clotting Time) greater than 450 seconds. In all patients, arterial cannulation was performed from the ascending aorta and the venous cannulation was provided by cannulation of both superior and inferior vena cava. The left superior pulmonary vein was used for vent cannulation. Mild hypothermia $\left(28\right.$ to $32^{\circ} \mathrm{C}$ ) was established during all cases. Antegrade and retrograde blood cardioplegia were supplied to each patient through appropriate cannulation. A retrograde coronary sinus cannula was inserted transatrially for cardioplegia infusions. The first isothermic blood cardioplegia infusion was given antegrade via an aortic root for 3 min then repeated every 20 minutes which was followed by a continuous infusion of retrograde cardioplegia. Cardioplegia include $0.3 \mathrm{mEq} \mathrm{kg}-1 \mathrm{KCL}$ within $10 \mathrm{ml} \mathrm{kg}-1$ of pump blood as well as appropriate doses of $\mathrm{MgSO} 4$ and $\mathrm{NaHCO} 3$. Retrograde cardioplegia was provided at a rate of $50 \mathrm{ml} \mathrm{min}-1$ with addition of appropriate doses of the same electrolytes in every $500 \mathrm{ml}$ of pump blood. Cardiopulmonary bypass circulation was provided by a roller Biomedicus pump (Biomedicus, Germany) in all patients. Systemic blood flow during CPB was kept between 2-2.5 L min-1 m2-1 and systemic blood pressure was kept between 50 to $80 \mathrm{mmHg}$. Arterial blood gas values are followed every 60 minutes to keep the levels as; $\mathrm{PO} 2$ greater than $250 \mathrm{mmHg}, \mathrm{PCO} 2$ between 35 to 45 $\mathrm{mmHg}, \mathrm{pH}$ between 7.35 to 7.40 , hematocrit between 22 to $28 \%$, blood sugar between 100 to $180 \mathrm{mg} \mathrm{dL}-1$. The operating time, type of oxygenator, quantity of blood prime used, and the types and numbers of valves replaced were recorded.

After rewarming with a $37^{\circ} \mathrm{C}$ maximal heat-exchanger temperature, $\mathrm{CPB}$ was discontinued at $36-37^{\circ} \mathrm{C}$ nasopharyngeal temperature. Intraoperative ventricular tachyarrhythmias were treated with internal cardioversion or lidocaine (1-1.5 mg kg-1). Reversal of heparin was 
achieved with protamine $1 \mathrm{mg}$ per milligram of heparin. Inotropic support, initially with dopamine $(5-10 \mu \mathrm{g} \mathrm{kg}-1$ min-1) and secondly with dobutamine (5-10 $\mu \mathrm{g} \mathrm{kg-1}$ min-1) and/or epinephrine (0.02-0.15 $\mu \mathrm{g} \mathrm{kg-1} \mathrm{min-1),}$ was commenced if the mean arterial pressure (MAP) was $<65 \mathrm{~mm} \mathrm{Hg}$ in the presence of a pulmonary artery wedge pressure (PAWP) of $15 \mathrm{~mm} \mathrm{Hg}$ and a heart rate of 70-110 beats $\min -1$.

In patients with coronary artery disease, distal anastomosis was completed by the use of saphenous veins and then the replacement or repair of the mitral valve was performed. After this procedure, mitral valve reconstruction was controlled by transmitral injection of the intraventricular isotonic sodium chloride solution and additional sutures were done if needed. Under partial cross clamp, proximal saphenous anastomosis was performed.

Statistical analysis.

All analyses were performed using SPSS Statistical Package 15.0 (SPSS Inc., California, USA). Patients' baseline characteristics in Group 1 and 2 are reported as mean (sd), frequencies and percentages. Differences were assessed using $\chi 2$ or the Fisher exact test for categorical variables and Mann-Whitney U-test for continuous or nonparametric data. For repeated measure analysis of the data, Friedman nonparametric one-way repeated measure analysis of variance by ranks is used to compare three or more matched groups. Interaction analysis revealed whether effects of time (repetitive measurements) were different between groups. $\mathrm{P}$ values $<0.05$ was considered statistically significant.

\section{Results}

The mean age of the whole group of 64 patients were $67.40 \pm 9.33$. Fifteen patients were female $(23 \%)$ whereas, 49 were male $(77 \%)$. Group 1 consisted of 36 patients whereas, Group 2 had 28 patients. The demographic data were similar in both group of patients ( $p>0.05)$ except, male gender was greater in Group 1 in comparison to Group 2 ( $\mathrm{p}<0.01)$ (Table 2).

Table 2. The comparison of demographic data in Group 1 and 2.

\begin{tabular}{|c|c|c|c|}
\hline & Group $1(n=36)$ & Group $2(n=28)$ & $\mathbf{p}^{*}$ \\
\hline Age & $56.31 \pm 13.14$ & $56.92 \pm 10.77$ & 0.86 \\
\hline Gender (Male/Female) $(\%)$ & 23/13(64/36) & $26 / 2(93 / 7)$ & $0.007 *$ \\
\hline Height $(\mathrm{cm})$ & $159.44 \pm 8.11$ & $157.64 \pm 6.76$ & 0.56 \\
\hline Weight (kg) & $66.94 \pm 12.64$ & $68.93 \pm 11.87$ & 0.73 \\
\hline BMI (kg m2-1) & $26.77 \pm 7.64$ & $27.77 \pm 8.64$ & 0,66 \\
\hline Preoperative serum urea (mg dL-1) & $45.39 \pm 25.22$ & $60.11 \pm 28.45$ & $0.01 *$ \\
\hline Preoperative serum creatinine (mg dL-1) & $0.88 \pm 0.12$ & $1.37 \pm 0.28$ & $<0.001 *$ \\
\hline Preoperative $\mathrm{EF}^{*}(\%)$ & $33.25 \pm 8.68$ & $34.50 \pm 9.92$ & 0.90 \\
\hline Mitral insufficiency $(\mathrm{n}, \%)$ & $36(100)$ & $28(100)$ & 1.00 \\
\hline Tricuspid insufficiency (n, \%) & $13(36)$ & $10(36)$ & 0.97 \\
\hline $\mathrm{CAD} *(\mathrm{n}, \%)$ & $9(25)$ & $8(28.6)$ & 0.75 \\
\hline $\mathrm{PHT}^{*}(\mathrm{n}, \%)$ & $9(25)$ & $8(28.6)$ & 0.75 \\
\hline \multicolumn{4}{|l|}{ Cardiovascular risk factors } \\
\hline Diabetes mellitus (non-insulin dependent) (n, \%) & $5(18)$ & $6(17)$ & 0.90 \\
\hline Hypertension $(\mathrm{n}, \%)$ & $13(36)$ & $10(35.7)$ & 0.97 \\
\hline Hypercholesterolemia (n, \%) & $2(5,6)$ & $4(14.3)$ & 0.24 \\
\hline Obesity $(\mathrm{n}, \%)$ & $2(5,6)$ & $3(10.7)$ & 0.45 \\
\hline History of smoking & $7(25)$ & $8(22)$ & 0.80 \\
\hline \multicolumn{4}{|l|}{ Co-existing diseases } \\
\hline $\operatorname{COPD}^{*}(\mathrm{n}, \%)$ & $5(18)$ & $6(17)$ & 0.90 \\
\hline $\mathrm{PAH}^{*}(\mathrm{n}, \%)$ & $2(5.6)$ & $4(14.3)$ & 0.24 \\
\hline Other $(\mathrm{n}, \%)$ & $2(5.6)$ & $3(10.7)$ & 0.45 \\
\hline \multicolumn{4}{|l|}{ Drug use effecting preoperative renal functions } \\
\hline Diuretics & $36(100)$ & $28(100)$ & 1.00 \\
\hline Beta blockers & $13(36)$ & $10(35,7)$ & 0.97 \\
\hline Calcium channel blockers & $5(18)$ & $6(17)$ & 0.90 \\
\hline ACE inhibitors & $13(36)$ & $10(35,7)$ & 0.97 \\
\hline Angiotensin receptor blockers & $7(25)$ & $8(22)$ & 0.80 \\
\hline
\end{tabular}

Patients with insulin dependent diabetes mellitus were not included in the study. The distribution of mitral and/or tricuspid insufficiency, coronary artery disease and pulmonary hypertension showed no difference $(\mathrm{p}>0.05)$ (Table 2). The comparison of the operative data showed that there were no significant differences between groups 
in parameters including; aortic cross-clamp time, cardiopulmonary bypass time, distribution of different operative procedures depending on preoperative diagnosis, postoperative 48-hour echocardiographic evaluation that provided data on ejection fraction, mitral insufficiency and PHT ( $>>0.05)$ (Table 3).

Table 3. The comparison of operative parameters in Group 1 and 2.

\begin{tabular}{|c|c|c|c|}
\hline & $\begin{array}{c}\text { Group } 1 \\
(n=36)\end{array}$ & $\begin{array}{c}\text { Group } 2 \\
(\mathbf{n}=28)\end{array}$ & $\mathbf{p}^{*}$ \\
\hline Mitral reconstruction (n, \%) & $36(100)$ & $28(100)$ & 1.00 \\
\hline $\begin{array}{l}\text { Mitral reconstruction and } \\
\text { single vessel CABG * }(\mathrm{n}, \%)\end{array}$ & $5(14)$ & $3(11)$ & 0.70 \\
\hline $\begin{array}{l}\text { Mitral reconstruction and two } \\
\text { vessel CABG }(n, \%)\end{array}$ & $4(11)$ & $4(14)$ & 0.70 \\
\hline $\begin{array}{l}\text { Mitral reconstruction and } \\
\text { TDVA* }(\mathrm{n}, \%)\end{array}$ & $8(22)$ & $5(18)$ & 0.68 \\
\hline ACC* (minute) & $67.47 \pm 20.83$ & $67.21 \pm 17.29$ & 0.68 \\
\hline $\mathrm{CPB}^{*}$ (minute) & $90.58 \pm 29.03$ & $85.61 \pm 18.68$ & 0.64 \\
\hline Postoperative EF* (\%) & $31.24 \pm 4.68$ & $32.68 \pm 3.96$ & 0.90 \\
\hline $\begin{array}{l}\text { Postoperative mitral } \\
\text { Insufficiency }(\mathrm{n}, \%)\end{array}$ & $2(6)$ & $3(11)$ & 0.45 \\
\hline Postoperative PHT*(n, \%) & $2(5.6)$ & $3(10.7)$ & 0.45 \\
\hline \multicolumn{4}{|c|}{$\begin{array}{l}* \mathrm{p}<0.05 \text { statistically significant, CABG; coronary } \\
\text { artery bypass graft, TDVA; tricuspid De Vega, } \\
\text { ACC; aortic cross-clamp time, CPB; } \\
\text { cardiopulmonary bypass time, EF; ejection fraction, } \\
\text { PHT; pulmonary hypertension. }\end{array}$} \\
\hline
\end{tabular}

Table 4. The comparison of preoperative and postoperative serum urea and creatinine levels between Group 1 and 2.

\begin{tabular}{|c|c|c|c|}
\hline Parameters & $\begin{array}{c}\text { Group } 1 \\
(n=36)\end{array}$ & $\begin{array}{c}\text { Group } 2 \\
(n=28)\end{array}$ & $\mathbf{p}^{*}$ \\
\hline $\begin{array}{l}\text { Preop. urea } \\
\text { (mg dL-1) }\end{array}$ & $65.4 \pm 25.2$ & $60.1 \pm 28.5$ & 0.01* \\
\hline $\begin{array}{l}\text { Postop.urea } \\
\text { Day } 1\end{array}$ & $46.2 \pm 18.5$ & $59.6 \pm 28.7$ & 0.03* \\
\hline $\begin{array}{l}\text { Postop. urea } \\
\text { Day } 3\end{array}$ & $60.4 \pm 36.3$ & $61.6 \pm 33.9$ & 0.95 \\
\hline $\begin{array}{l}\text { Postop.urea } \\
\text { Day } 10\end{array}$ & $56.5 \pm 50.7$ & $57.9 \pm 25.2$ & 0.09 \\
\hline $\mathbf{p}$ & $0.001 *$ & 0.28 & \\
\hline $\begin{array}{l}\text { Preop. creatinine } \\
\quad(\mathrm{mg} \text { dL-1) }\end{array}$ & $0.88 \pm 0.1$ & $1.37 \pm 0.3$ & $<0.001 *$ \\
\hline $\begin{array}{c}\text { Postop. creatinine } \\
\text { Day } 1\end{array}$ & $1.05 \pm 0.4$ & $1.35 \pm 0.4$ & $<0.001 *$ \\
\hline $\begin{array}{l}\text { Postop. creatinine } \\
\text { Day } 3\end{array}$ & $1.01 \pm 0.5$ & $1.14 \pm 0.4$ & 0.06 \\
\hline $\begin{array}{l}\text { Postop. creatinine } \\
\text { Day } 10\end{array}$ & $1.04 \pm 0.7$ & $1.11 \pm 0.3$ & $0.02 *$ \\
\hline $\mathbf{p}$ & 0.10 & $<0.001 *$ & \\
\hline
\end{tabular}

Preoperative serum urea and creatinine levels were higher in Group 1 in comparison to Group 2 ( $\mathrm{p}=0.01$, $\mathrm{p}<0.001$, respectively). On postoperative day 1 , serum urea and creatinine levels of Group 1 was significantly lower than Group 2 (0.03 and $\mathrm{p}<0.001$, respectively). On postoperative day 3 and 10, no differences were observed between groups ( $\mathrm{p}>0.05)$ (Table 4).

In Group 1, serum urea levels showed a significant decrease in comparison of preoperative levels and postoperative day 1,3 and $10(\mathrm{p}=0.001)$ however, no difference was observed in Group 2 ( $p>0.05$ ) (Table 4). In Group 1, the comparison of serum creatinine levels showed no significant difference in repetitive measurement points whereas, in Group 2, the serum creatinine levels showed a significant decrease in comparison of preoperative levels and postoperative day 1,3 and $10(\mathrm{p}<0.001)$ (Figure 1 and 2).

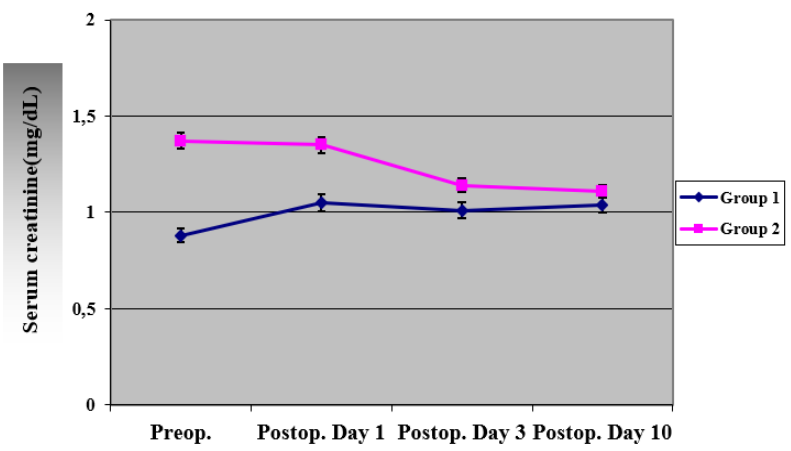

Figure 1. The comparison of the preoperative and postoperative serum creatinine levels on postoperative day 1,3 and 10 in Group 1 and 2.

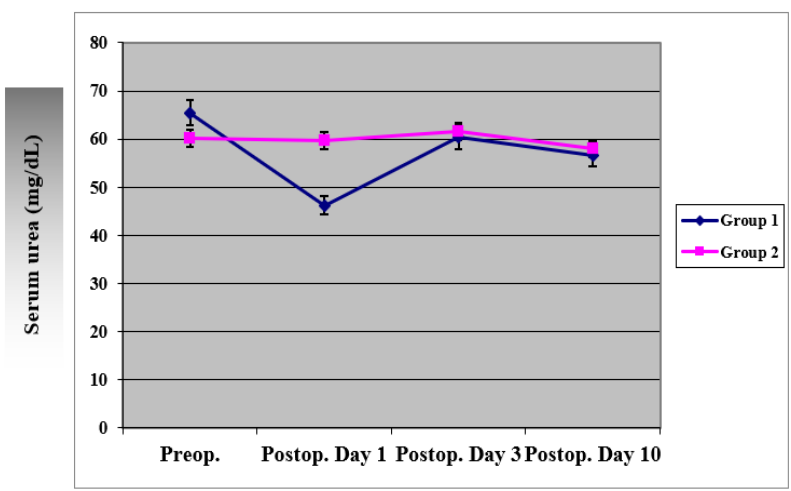

Figure 2. The comparison of the preoperative and postoperative serum urea levels on postoperative day 1,3 and 10 in Group 1 and 2.

The prognostic risk factors affecting morbidity in the first 10 day postoperatively showed no difference between groups $(\mathrm{p}>0.05)$ (Table 5). Low cardiac output state was reported in $2(6 \%)$ patients in Group 1, and $1(3 \%)$ patient in Group 2. In Group 1, 32 (89 \%) patients and in Group 2, $26(93 \%)$ patients required dobutamine and the need of epinephrine was $17(47 \%)$ and $10(36 \%)$ respectively. In Group 1, 8 patients (22\%) and in Group 210 patients $(36 \%)$ received renal dose of dopamine at a dose of $3 \mathrm{mcg}$ 
$\mathrm{kg}-1$ min-1. The use of IABP was 8 patients in Group 1 $(22 \%)$ and 8 patients in $(29 \%)$. The use of IABP were not different between groups. The requirement of dialysis was in 2 patients $(6 \%)$ in Group 1 and in 1 patient $(3 \%)$ in Group 2 and there was no significant difference between groups ( $>>0.05)$ (Table 5).

Three patients ( $8 \%$ ) in Group 1 and 1 patient $(4 \%)$ in Group 2 died within 30 days of surgery in the hospital.

Table 5. The comparison of postoperative parameters between Group 1 and 2.

\begin{tabular}{|l|c|c|c|}
\hline Parameters & $\begin{array}{c}\text { Grup 1 } \\
(\mathbf{n = 3 6})\end{array}$ & $\begin{array}{c}\text { Grup 2 } \\
(\mathbf{n = 2 8})\end{array}$ & p* \\
\hline Epinephrine (n, \%) & $17(47)$ & $10(36)$ & 0.36 \\
\hline Norepinephrine (n, \%) & $9(25)$ & $11(39)$ & 0.22 \\
\hline Dobutamine (n, \%) & $32(89)$ & $26(93)$ & 0.59 \\
\hline Dopamine (n, \%) & $8(22)$ & $10(36)$ & 0.17 \\
\hline Dialysis & $2(6)$ & $1(3)$ & 0.71 \\
\hline IABP* & $8(22)$ & $8(29)$ & 0.56 \\
\hline Mortality (\%) & $3(8)$ & $1(4)$ & 0.44 \\
\hline
\end{tabular}

The prognostic factors effecting morbidity in the first 10 day postoperatively

\begin{tabular}{|c|c|c|c|}
\hline Pneumonia (n, \%) & $2(6)$ & $3(11)$ & 0.45 \\
\hline $\begin{array}{l}\text { Prolonged mechanical } \\
\text { ventilation }(\mathrm{n}, \%)\end{array}$ & $3(8)$ & $3(11)$ & 0.59 \\
\hline Myocardial infarction & $2(6)$ & $3(11)$ & 0.45 \\
\hline Atrial Fibrillation & $2(6)$ & $3(11)$ & 0.45 \\
\hline Other rhythm disturbances & $5(14)$ & $3(11)$ & 0.70 \\
\hline Permanent pacemaker & $1(2)$ & $1(3)$ & 0.33 \\
\hline $\begin{array}{l}\text { Reoperation secondary to } \\
\text { bleeding }\end{array}$ & $2(6)$ & $2(7)$ & 0.41 \\
\hline Cerebrovascular event & $5(14)$ & $4(14)$ & 0.63 \\
\hline $\begin{array}{l}\text { Low cardiac output } \\
\text { syndrome }\end{array}$ & $2(6)$ & $1(3)$ & 0.71 \\
\hline Intensive care unit stay (day) & $4.30 \pm 2.9$ & $4.68 \pm 2.8$ & 0.50 \\
\hline Hospital stay (day) & $9.89 \pm 3.9$ & $10.39 \pm 5.0$ & 0.31 \\
\hline
\end{tabular}

\section{Discussion}

In this retrospective study where the renal effects of levosimendan in patients undergoing open heart surgery with low ejection fraction is sought, our most significant finding is that patients having preoperative serum creatinine level of greater than $1.2 \mathrm{mg} \mathrm{dL}-1$ had a decrease in the level of serum creatinine in the first 10 days postoperatively in comparison to the preoperative level whereas, patients having a preoperative serum creatinine level of less than $1.2 \mathrm{mg}$ dL-1 had maintained their level of serum creatinine. This study provides data on the clinical effects of levosimendan on serum creatinine levels in patients with low ejection fraction undergoing open-heart surgery with $\mathrm{CPB}$.

The effects of levosimendan on kidney functions after open-heart surgeries with $\mathrm{CPB}$ has been studied in randomized clinical studies especially in patients with a diagnosis of low cardiac output [18-22]. A study by Yilmaz and his colleagues demonstrated that in a group of 88 patients with heart failure (HF), intravenous levosimendan infusion showed beneficial effects on glomerular filtration rate (GFR) 24 and 72 hours after surgery when compared to a group of patients receiving a traditional inotrope which is dobutamine [18]. The preoperative and postoperative 24and 72-hours glomerular filtration rate (GFR) median values were compared providing data that in group of patients that received levosimendan had higher GFR values in comparison to patients with dobutamine at 24 hours after surgery and GFR increased by $15.3 \%$ under levosimendan versus $-1.33 \%$ under dobutamine and a similar finding was observed at 72 hours after surgery as well [18]. In the study by Zemljic et al, 40 patients with severe congestive heart failure and increased serum creatinine values were enrolled and while half of the patients received levosimendan infusion the other half received no inotrope and these patients were followed for three months. The study evaluated the serum creatinine and creatinine clearance values of the patients which revealed that in comparison to the basal values before start of the study $(1.92 \pm 0.13 \mathrm{mg}$ $\mathrm{dL}-1)$, the patients in the levosimendan group showed reduced levels of serum creatinine $(1.60+/-0.26 \mathrm{mg} \mathrm{dL}-1$ vs. $1.90+/-0.14 \mathrm{mg} \mathrm{dL}-1$, respectively $\mathrm{p}=0.005$ ) and increased creatinine clearance in comparison to the control group $(53.6+/-8.6 \mathrm{~mL}$ min-1 ve $44.0+/-3.3 \mathrm{~mL} \mathrm{~min}-1$, respectively, $p=0.005$ ) [20]. There are other recent studies that supports the beneficial clinical effects of levosimendan on serum creatinine levels in patients with low ejection fraction undergoing open heart surgeries with CPB. [1922]. In a meta-analysis study that reviewed 10 randomized controlled studies and included 440 patients, it has been reported that there were no differences in the parameters including myocardial infarction, acute renal failure, duration of mechanical ventilation, intensive care unit and hospital stay in comparison of levosimendan and control groups ( $p>0.05)$ [23].

Recent studies point out that the use of levosimendan may be beneficial in low cardiac output states after open heart surgery with CPB [18-26]. In our study, the prognostic risk factors effecting morbidity in the first 10 day postoperatively showed no difference between groups where serum creatinine $1.2 \mathrm{mg} \mathrm{dL}-1$ was a cut-off value for division of the patients into two groups. (Table 5). Recent studies point out that the use of levosimendan may be beneficial in low cardiac output states after open heart surgery with CPB [23-25,27]. The most common factors 
correlating with the need for inotropic or vasoactive support at the time of CPB separation are female sex, older age, low ejection fraction, cardiac enlargement, diastolic dysfunction, longer duration of $\mathrm{CPB}$, and longer duration of aortic cross-clamp time [28]. In our study, low cardiac output state was reported in $2(6 \%)$ patients in Group 1, and $1(3 \%)$ patient in Group 2. This finding is important in transient myocardial dysfunction, which is more pronounced in patients with impaired left ventricular function before surgery, resulting in the need for postoperative inotropic support [23,24,29]. The reduction of ejection fraction below $46 \%$ is associated with the need of inotropes in a range between $71 \%$ to $100 \%$ in the first 24 hours postoperatively after heart surgery [30]. These findings are similar to our study that around $90 \%$ of our patients required at least one inotrope and 30 to $40 \%$ of our patients required a second inotropic agent postoperatively in addition to levosimendan infusion in the first 24 hours. It has been discussed in the literature that cardiac surgical patients with postoperative myocardial dysfunction resistant to dobutamine, the addition of levosimendan to dobutamine was effective in reversing LCOS, a complication with an estimated prevalence of about $10 \%$ and a mortality of $17 \%$ [26,27,31]. The vasodilator and inotropic therapies, as well as intra-aortic balloon counterpulsation is frequently used to restore adequate tissue perfusion in the immediate postoperative period especially in critically ill intensive care unit patients and in patients with cardiogenic shock after cardiac surgery. [27,31-34]. The use of IABP in our study was between 22 and $29 \%$ ( $>>0.05)$.

Acute kidney injury (AKI) in the postoperative cardiac surgery population remains a significant cause of perioperative morbidity and mortality. The postoperative incidence of AKI ranges between $5 \%$ to $20 \%$ and has been reported to be associated with increased mortality up to $60 \%$ among patients requiring dialysis. Postoperative renal insufficiency is defined as a 2-fold or greater elevation of creatinine that must exceed $2.0 \mathrm{mg} / \mathrm{dL}$ whereas, renal failure is defined as AKI requiring dialysis by The Society of Thoracic Surgeons [32]. Specific risk factors were identified and these include; advanced age, diabetes, congestive heart failure, low cardiac index, preexisting renal dysfunction, and more complex cardiac surgery. [23-27,30-34].

There are several clinical studies that investigated the renal effects of levosimendan in patients undergoing openheart surgeries and a recent meta-analysis reveals that, in a total of six randomized clinical trials including 1200 patients with preoperative reduced low EF of less than $35 \%$, mortality was reduced with levosimendan as compared to placebo and levosimendan significantly decreased the need for postoperative renal replacement therapy after open-heart surgeries with CPB [32].
Cardiopulmonary bypass time was not found as a risk factor for the development of AKI. The role of age is stil under debate as well. [23,27]. In the study by Barkhordari and his colleagues, the risk factors for AKI include; preoperative serum creatinine, advanced age, combined valvular and CABG operation procedure [31]. In a metaanalysis study that reviewed 10 randomized controlled studies and included 440 patients, there were no differences in the parameters including myocardial infarction, acute renal failure, duration of mechanical ventilation, intensive care unit and hospital stay in comparison of levosimendan and control groups [23,32]. We also considered preoperative creatinine value and combined valvular and CABG operation procedures under risk of AKI and for this reason we retrospectively analyzed the data of patients undergoing open-heart surgeries with CPB with preoperative low EF of less than $40 \%$.

The risk of AKI that requires dialysis is reported to be low and has been reported to range between $1.1 \%$ and $3 \%$ [31-34]. In our study 2 patients (6\%) in Group 1 and 1 (3\%) patient in Group 2 required dialysis and the incidence of dialysis was over all $4.7 \%$. A dose reduction of the levosimendan in patients who have higher serum creatinine levels have been put forward however, recent data showed that there is no need for dose reduction. In our study, we did not observe a need for a dose reduction and no significant side effects were reported [27,32]. A metaanalysis by Harrison and colleagues also highlighted the beneficial effects of perioperative levosimendan on renal function, as it showed significant reductions in the need for dialysis in levosimendan-treated patients $(\mathrm{P}=0.003)$ [24]. There were several consensus papers on the overall renal effects of levosimendan in the literature [19,23,24,26,27,30-34].

The present study has the limitations inherent to the small number of patients and the lack of a control group however, our result on serum urea and creatinine values provides valuable data for further research on larger group of patients with levosimendan that includes randomized clinical trials with addition of a placebo group.

\section{Conclusions}

Recently, levosimendan has been studied for patients with low left ventricular ejection fraction undergoing openheart surgery with $\mathrm{CPB}$ and there is a consensus on its use for patients with low ejection fraction as it decreases mortality and also reduces the need for renal replacement therap. Levosimendan has systemic effects on hemodynamical parameters as it increases the cardiac output, causes preglomerular vasodilation, antiinflammatory, and antiapoptotic effects leading to an improved immediate postoperative renal function and reduced need for renal replacement therapy. This is in line with our findings, showing a significantly decreased 
incidence of postoperative acute kidney injury and a need for renal replacement therapy in patients receiving levosimendan for open-heart surgeries with CPB.

In patients with low ejection fraction undergoing openhearted surgeries, the use of levosimendan intraoperatively and for a duration of twenty-four hours postoperatively has a potential role of prevention of deterioration of renal functions in all patients regardless of the preoperative serum creatinine level.

\section{Conflict of interest disclosure}

There are no known conflicts of interest in the publication of this article. The manuscript was read and approved by all authors.

\section{Compliance with ethical standards}

Any aspect of the work covered in this manuscript has been conducted with the ethical approval of all relevant bodies and that such approvals are acknowledged within the manuscript.

\section{References}

1. Essay P, Balkan B, Subbian V. Decompensation in Critical Care: Early Prediction of Acute Heart Failure Onset. JMIR Med Inform. 2020 Aug 7;8(8):e19892. doi: 10.2196/19892

2. Chen WC, Lin MH, Chen CL, Chen YC, Chen CY, Lin YC, Hung CC. Comprehensive Comparisons among Inotropic Agents on Mortality and Risk of Renal Dysfunction in Patients Who Underwent Cardiac Surgery: A Network Meta-Analysis of Randomized Controlled Trials. J Clin Med. 2021 Mar 3;10(5):1032. doi: 10.3390/jcm10051032

3. Glinka L, Mayzner-Zawadzka E, Onichimowski D, Jalali R, Glinka M. Levosimendan in the modern treatment of patients with acute heart failure of various aetiologies. Arch Med Sci. 2019 Nov 7;17(2):296-303. doi: 10.5114/aoms.2018.77055

4. Papp Z, Édes I, Fruhwald S, De Hert SG, Salmenperä M, Leppikangas H, Mebazaa A, Landoni G, Grossini E, Caimmi P, Morelli A, Guarracino F, Schwinger RH, Meyer S, Algotsson L, Wikström BG, Jörgensen K, Filippatos G, Parissis JT, González MJ, Parkhomenko A, Yilmaz MB, Kivikko M, Pollesello P, Follath F. Levosimendan: molecular mechanisms and clinical implications: consensus of experts on the mechanisms of action of levosimendan. Int J Cardiol. 2012 Aug 23;159(2):82-7. doi: 10.1016/j.ijcard.2011.07.022

5. Follath F, Cleland JG, Just H, Papp JG, Scholz H, Peuhkurinen K, Harjola VP, Mitrovic V, Abdalla M, Sandell EP, Lehtonen L; Steering Committee and Investigators of the Levosimendan Infusion versus Dobutamine (LIDO) Study. Efficacy and safety of intravenous levosimendan compared with dobutamine in severe low-output heart failure (the LIDO study): a randomised double-blind trial. Lancet. $2002 \mathrm{Jul}$ 20;360(9328):196-202. doi: 10.1016/s01406736(02)09455-2

6. Iyngkaran P, Thomas M, Majoni W, Anavekar NS, Ronco C. Comorbid Heart Failure and Renal Impairment: Epidemiology and Management. Cardiorenal Med. 2012 Dec;2(4):281-297. doi: 10.1159/000342487

7. Sparks MA, Crowley SD, Gurley SB, Mirotsou M, Coffman TM. Classical Renin-Angiotensin system in kidney physiology. Compr Physiol. 2014 Jul;4(3):1201-28. doi: 10.1002/cphy.c130040

8. Lee SA, Cozzi M, Bush EL, Rabb H. Distant Organ Dysfunction in Acute Kidney Injury: A Review. Am J Kidney Dis. 2018 Dec;72(6):846-856. doi: 10.1053/j.ajkd.2018.03.028

9. Karim HM, Yunus M, Saikia MK, Kalita JP, Mandal M. Incidence and progression of cardiac surgeryassociated acute kidney injury and its relationship with bypass and cross clamp time. Ann Card Anaesth. 2017 Jan-Mar;20(1):22-27. doi: 10.4103/0971-9784.197823

10. Candela-Toha A, Elías-Martín E, Abraira V, Tenorio MT, Parise D, de Pablo A, Centella T, Liaño F. Predicting acute renal failure after cardiac surgery: external validation of two new clinical scores. Clin J Am Soc Nephrol. 2008 Sep;3(5):1260-5. doi: 10.2215/CJN.00560208

11. Thakar CV, Arrigain S, Worley S, Yared JP, Paganini EP. A clinical score to predict acute renal failure after cardiac surgery. J Am Soc Nephrol. 2005 Jan;16(1):162-8. doi: 10.1681/ASN.2004040331

12. Puttonen J, Kantele S, Kivikko M, Häkkinen S, Harjola VP, Koskinen P, Pentikäinen PJ. Effect of severe renal failure and haemodialysis on the pharmacokinetics of levosimendan and its metabolites. Clin Pharmacokinet. 2007;46(3):235-46. doi: 10.2165/00003088-20074603000004

13. Pataricza J, Krassói I, Höhn J, Kun A, Papp JG. Functional role of potassium channels in the vasodilating mechanism of levosimendan in porcine isolated coronary artery. Cardiovasc Drugs Ther. 2003 Mar;17(2):115-21. doi: 10.1023/a:1025331617233

14. Paraskevaidis IA, Parissis JT, Th Kremastinos D. Antiinflammatory and anti-apoptotic effects of levosimendan in decompensated heart failure: a novel mechanism of drug-induced improvement in contractile performance of the failing heart. Curr Med Chem Cardiovasc Hematol Agents. 2005 Jul;3(3):2437. doi: 10.2174/1568016054368232

15. Goldfarb M, Abassi Z, Rosen S, Shina A, Brezis M, Heyman SN. Compensated heart failure predisposes to outer medullary tubular injury: studies in rats. Kidney 
Int. 2001 Aug;60(2):607-13. doi: 10.1046/j.15231755.2001.060002607.x

16. John B, Babu M, Shaji S, Abraham S, Abdullakutty J. Clinical outcomes of levosimendan versus dobutamine in patients with acute decompensated heart failure with reduced ejection fraction and impaired renal function. Indian Heart J. 2021 May-Jun;73(3):372-375. doi: 10.1016/j.ihj.2021.02.010

17. Castelvecchio S, Menicanti L, Baryshnikova E, de Vincentiis C, Frigiola A, Ranucci M; Surgical and Clinical Outcome Research (SCORE) Group. Comparison of morbidity and mortality in diabetics versus nondiabetics having isolated coronary bypass versus coronary bypass plus valve operations versus isolated valve operations. Am J Cardiol. 2011 Feb 15;107(4):535-9. doi: 10.1016/j.amjcard.2010.10.009

18. Yilmaz MB, Yalta K, Yontar C, Karadas F, Erdem A, Turgut OO, Yilmaz A, Tandogan I. Levosimendan improves renal function in patients with acute decompensated heart failure: comparison with dobutamine. Cardiovasc Drugs Ther. 2007 Dec;21(6):431-5. doi: 10.1007/s10557-007-6066-7

19. Chen WC, Lin MH, Chen CL, Chen YC, Chen CY, Lin YC, Hung CC. Comprehensive Comparisons among Inotropic Agents on Mortality and Risk of Renal Dysfunction in Patients Who Underwent Cardiac Surgery: A Network Meta-Analysis of Randomized Controlled Trials. J Clin Med. 2021 Mar 3;10(5):1032. doi: 10.3390/jcm10051032

20. Göçer S, Karaçalilar M, Yazici S, Aydin C. Use of native $\mathrm{Y}$-saphenous vein graft in multi-vessel coronary bypass surgery. J Clin Invest Surg. 2020;5(2):96-99. doi: 10.25083/2559.5555/5.2/96.99

21. Baysal A, Yanartas M, Dogukan M, Gundogus N, Kocak T, Koksal C. Levosimendan improves renal outcome in cardiac surgery: a randomized trial. $J$ Cardiothorac Vasc Anesth. 2014 Jun;28(3):586-94. doi: 10.1053/j.jvca.2013.09.004

22. Bragadottir G, Redfors B, Ricksten SE. Effects of levosimendan on glomerular filtration rate, renal blood flow, and renal oxygenation after cardiac surgery with cardiopulmonary bypass: a randomized placebocontrolled study. Crit Care Med. 2013;41(10):2328-35. doi: 10.1097/CCM.0b013e31828e946a

23. Landoni G, Mizzi A, Biondi-Zoccai G, Bruno G, Bignami E, Corno L, Zambon M, Gerli C, Zangrillo A. Reducing mortality in cardiac surgery with levosimendan: a meta-analysis of randomized controlled trials. J Cardiothorac Vasc Anesth. 2010 Feb;24(1):51-7. doi: 10.1053/j.jvca.2009.05.031

24. Harrison RW, Hasselblad V, Mehta RH, Levin R, Harrington RA, Alexander JH. Effect of levosimendan on survival and adverse events after cardiac surgery: a meta-analysis. J Cardiothorac Vasc Anesth. 2013 Dec;27(6):1224-32. doi: 10.1053/j.jvca.2013.03.027

25. Labriola C, Siro-Brigiani M, Carrata F, Santangelo E, Amantea B. Hemodynamic effects of levosimendan in patients with low-output heart failure after cardiac surgery. Int J Clin Pharmacol Ther. 2004 Apr;42(4):204-11. doi: 10.5414/cpp42204

26. Landoni G, Lomivorotov VV, Alvaro G, Lobreglio R, Pisano A, Guarracino F, Calabrò MG, Grigoryev EV, Likhvantsev VV, Salgado-Filho MF, Bianchi A, Pasyuga VV, Baiocchi M, Pappalardo F, Monaco F, Boboshko VA, Abubakirov MN, Amantea B, Lembo R, Brazzi L, Verniero L, Bertini P, Scandroglio AM, Bove T, Belletti A, Michienzi MG, Shukevich DL, Zabelina TS, Bellomo R, Zangrillo A; CHEETAH Study Group. Levosimendan for Hemodynamic Support after Cardiac Surgery. N Engl J Med. 2017; 376(21):2021-2031. doi: 10.1056/NEJMoa1616325

27. Cholley B, Caruba T, Grosjean S, Amour J, Ouattara A, Villacorta J, Miguet B, Guinet P, Lévy F, Squara P, Aït Hamou N, Carillion A, Boyer J, Boughenou MF, Rosier S, Robin E, Radutoiu M, Durand M, Guidon C, Desebbe O, Charles-Nelson A, Menasché P, Rozec B, Girard C, Fellahi JL, Pirracchio R, Chatellier G; -. Effect of Levosimendan on Low Cardiac Output Syndrome in Patients With Low Ejection Fraction Undergoing Coronary Artery Bypass Grafting With Cardiopulmonary Bypass: The LICORN Randomized Clinical Trial. JAMA. 2017 Aug 8;318(6):548-556. doi: 10.1001/jama.2017.9973

28. Bernard F, Denault A, Babin D, Goyer C, Couture P, Couturier A, Buithieu J. Diastolic dysfunction is predictive of difficult weaning from cardiopulmonary bypass. Anesth Analg. 2001 Feb;92(2):291-8. doi: 10.1097/00000539-200102000-00002

29. Eagle KA, Guyton RA, Davidoff R, Edwards FH, Ewy GA, Gardner TJ, Hart JC, Herrmann HC, Hillis LD, Hutter AM Jr, Lytle BW, Marlow RA, Nugent WC, Orszulak TA; American College of Cardiology; American Heart Association. ACC/AHA 2004 guideline update for coronary artery bypass graft surgery: a report of the American College of Cardiology/American Heart Association Task Force on Practice Guidelines (Committee to Update the 1999 Guidelines for Coronary Artery Bypass Graft Surgery). Circulation. 2004 Oct 5;110(14):e340-437

30. Lomivorotov VV, Efremov SM, Kirov MY, Fominskiy EV, Karaskov AM. Low-Cardiac-Output Syndrome After Cardiac Surgery. J Cardiothorac Vasc Anesth. 2017;31(1):291-308. doi: 10.1053/j.jvca.2016.05.029

31. Barkhordari K, Fakhre Yasseri AM, Yousefshahi F, Shafiee A. Risk Factors for Acute Kidney Injury in 
Coronary Artery Bypass Graft Surgery Patients Based on the Acute Kidney Injury Network Criteria. J Tehran Heart Cent. 2018 Apr;13(2):52-57.

32. Sanfilippo F, Knight JB, Scolletta S, Santonocito C, Pastore F, Lorini FL, Tritapepe L, Morelli A, Arcadipane A. Levosimendan for patients with severely reduced left ventricular systolic function and/or low cardiac output syndrome undergoing cardiac surgery: a systematic review and meta-analysis. Crit Care. 2017 Oct 19;21(1):252. doi: 10.1186/s13054-017-1849-0
33. Manea M, Bratu OG, Bacalbasa N, Diaconu CC. Diagnosis and management of pericardial effusion. $J$ Mind Med Sci. 2020; 7(2): 148-155. doi: 10.22543/7674.72.P148155

34. Guarracino F, Heringlake M, Cholley B, Bettex D, Bouchez S, Lomivorotov VV, Rajek A, Kivikko M, Pollesello P. Use of Levosimendan in Cardiac Surgery: An Update After the LEVO-CTS, CHEETAH, and LICORN Trials in the Light of Clinical Practice. $J$ Cardiovasc Pharmacol. 2018 Jan;71(1):1-9. doi: 10.1097/FJC.0000000000000551 